\title{
Quando há cartel?
}

\section{Carolina Escobar de Almeida Prado}

\begin{abstract}
Resumo
Ao fundar a Escola Francesa de Psicanálise, Lacan propõe que, no cerne da Escola, estariam duas formas peculiares de experimentar e transmitir a experiência psicanalítica: o passe e o cartel. Este artigo tem por objetivo levantar impasses do dispositivo do cartel a partir de uma experiência de dissolução; para isso, levanta três elementos - forma, tempo e espaço - para a problematização do dispositivo no que tange a seu caráter inédito e potente para a formação dos analistas.
\end{abstract}

\section{Palavras-chave:}

Psicanálise; Lacan; Escola; Cartel.

\section{When is there cartel?}

\begin{abstract}
When Jacques Lacan founded the French School of Psychoanalysis, he proposed that at the center of the School two peculiar ways of experiencing and transmitting the psychoanalytic experience would exist: the pass and the cartel. This article aims to discuss some impasses of the cartel device from an experience of dissolution; for this, it raises three elements - form, time and space - to problematize this type of device when it comes to its unprecedented and potent character for the education as an analyst.
\end{abstract}

\section{Keywords:}

Psychoanalysis; Lacan; School; Cartel.

\section{¿Cuando hay cartel?}

\section{Resumen}

Al fundar la Escuela Francesa de Psicoanálisis, Jacques Lacan propone que en el corazón de la Escuela estarían dos formas peculiares de experimentar y transmitir la experiencia psicoanalítica: el pase y el cartel. Este artículo tiene por objetivo 
enumerar impasses del dispositivo del cártel a partir de una experiencia de disolución; para eso, discute tres elementos - forma, tiempo y espacio - para la problematización del dispositivo en relación a su carácter inédito y potente para la formación de los analistas.

\section{Palabras claves:}

Psicoanálisis; Cartel; Escuela; Lacan.

\section{Quand il y a cartel ?}

\section{Résumé}

Lorsqu'il fonde l'École Française de Psychanalyse, Jacques Lacan propose qu'il y ait, dans son sein, deux manières particulières d'expérimenter et de transmettre l'expérience psychanalytique : la passe et le cartel. Ainsi, cet article a pour but de poser les impasses du dispositif du cartel à partir d'une expérience de dissolution ; pour y arriver, trois éléments - la forme, le temps et l'espace - sont étudiés, ayant en compte la problématisation du dispositif par rapport à son caractère inédit et puissant quant à la formation des analystes.

\section{Mots-clés :}

Psychanalyse ; Lacan ; École ; Cartel.

(...) a experiência não decepcionará, nós o garantimos, aqueles que conservam um certo gosto pelo espantar-se.

(Lacan, 1945/1998, p. 199)

Após ser proibido de ser analista didata na International Psychoanalytical Association (IPA), Jacques Lacan decide desligar-se dessa escola de psicanálise. A proibição que lhe foi concedida permitia que frequentasse as aulas e os eventos que lá aconteciam, mas estava impedido de se envolver com o elemento central de uma escola de psicanálise: a formação dos analistas.

Até os dias atuais, os analistas didatas são aqueles que, entre os analistas, estariam autorizados a se ocupar do atendimento daqueles que querem ser analistas; portanto, têm lugar fundamental no que diz respeito à definição do fazer psicanalítico. "Ser psicanalista num certo momento era praticamente 'ser e pensar' como o analista didata, a referência possível e mais presente" (Azevedo, 2008, p. 180). 
A proibição de ser analista didata demonstra um posicionamento político da IPA, que o impede de se ocupar do futuro da psicanálise. Diante disso, Lacan explicita fortes críticas aos princípios que organizam essa escola de psicanálise, que, segundo ele, dariam origem a

(...) uma prática mitigada pela irrupção de uma psicoterapia associada às necessidades da higiene mental (...) em que a prática aqui denunciada assume uma forma imperialista - conformismo da mirada, barbarismo da doutrina, regressão rematada a um psicologismo puro e simples, tudo isso mal compensado pela promoção de um clericato fácil de caricaturar. (Lacan, 1964/2003, p. 243)

Tomado por isso, Lacan decide romper seu vínculo com a IPA e, em junho de 1964, escreve o Ato de fundação de sua Escola (Escola Francesa de Psicanálise). Nesse movimento, propõe que, no cerne da Escola, estariam duas formas peculiares de experimentar e transmitir a experiência psicanalítica: o passe e o cartel.

Sua compreensão da formação do analista é caracterizada por um ineditismo provocativo, uma vez que os dois dispositivos que ele inventa como proposta partem da premissa de que “(...) o ensino da psicanálise só pode transmitir-se de um sujeito para outro pelas vias da transferência de trabalho" (Lacan, 1964/2003, p. 242).

É uma proposta de formação radicalmente distinta da que até então existia. Em sua Escola, a execução do trabalho seria apoiada em pequenos grupos organizados de forma circular e sem uma hierarquia presente. A ideia central firma-se no que é vivenciado na experiência, e sua proposta é pautada pela preocupação com os possíveis desvios e com o destino da práxis psicanalítica. A radicalidade está quando “(...) deixamos a cargo de cada um descobrir suas promessas e seus obstáculos. Àqueles que puderem interrogar-se sobre o que nos guia (...)” (Lacan, 1964/2003, p. 242). É tenho como base esse princípio que este texto apresenta sua proposta.

Muitas vezes, ouvi durante debates sobre os dispositivos da Escola que vivenciar a dissolução de um cartel é uma experiência curiosa. Ela acontece quando uma das pessoas que compõem o cartel escolhe não lhe dar continuidade; as razões que levam alguém a isso são inúmeras e irrelevantes agora, mas o fato é que basta uma pessoa deixar de endereçar àquele cartel o lugar para transmissão e construção da psicanálise para que o cartel deixe de existir. Assim como em um nó borromeano que, quando um elo se solta, todos estão soltos, dissolvem-se.

Vivi essa experiência no primeiro cartel de minha formação. Por e-mail, eu e meus colegas de cartel recebemos a notícia de que determinado cartelizante havia decidido interromper o trabalho por ter iniciado uma nova profissão e, por isso, a psicanálise não lhe fazia mais sentido. De pronto entendi que isso implicaria a interrupção daquele trabalho, não só para quem havia desistido, mas também para todos nós. 
Foi preciso tempo e certo decantamento da experiência para que eu pudesse assimilar o que havia acontecido ali. No começo de minha formação, incitando o contato com uma escola de psicanálise e com a própria teoria lacaniana, não me foi possível pôr em questão o dispositivo, seus princípios e objetivos. A ânsia por entendê-lo veio depois e, só então, a vontade de escrever.

Ao pensar no que aconteceu ali, entre as perguntas que aparecem, a que mais se faz presente é: quando há cartel? Usarei essa pergunta como motor para tentar localizar os impasses de um dispositivo como esse na intenção de cuidar para que ele mantenha seu caráter inédito e potente para a formação dos analistas.

Levanto três elementos que gostaria de problematizar neste momento. Vamos a eles.

\section{Forma}

Advertido do que não gostaria em que sua Escola se transformasse, Lacan determina algumas condições para o funcionamento de um cartel na intenção de evitar os efeitos grupo, mestria e unidade, que tendem a ocorrer quando pessoas trabalham juntas.

Para a execução do trabalho, adotaremos o princípio de uma elaboração apoiada num pequeno grupo. Cada um deles (...) se comporá de no mínimo três pessoas e no máximo cinco, sendo quatro a justa medida. MAIS UM encarregado da seleção, da discussão e do destino a ser reservado ao trabalho de cada um.

Após um certo tempo de funcionamento, os componentes de um grupo verão ser-lhes proposta a permuta para outro. (Lacan, 1964/2003, p. 235)

Fica explícito que o envolvimento com a formação ocorre pela via do trabalho, e que a singularidade é levada em conta nesse processo. A proposta do psicanalista para esse dispositivo é bastante interessante, quando aposta que a apropriação da práxis psicanalítica viria a partir da implicação com ela.

Essa implicação não se dá da mesma maneira para todos os cartelizantes, assim como o envolvimento de cada um com essa práxis. No cartel, a singularidade está posta desde a pergunta - teórica e/ou clínica - de cada um quando escolhe se envolver com o tema que norteará o cartel; no processo, pelo compromisso com a pesquisa e, no fim, na responsabilidade de compartilhar os achados com a comunidade analítica.

No entanto, será que as condições apontadas por Lacan como necessárias para o funcionamento de um cartel garantiriam que houvesse a transmissão de seu ensino?

O termo "garantia" é problemático, mas ele está nessa pergunta de forma intencional. Se, na vivência de cartel, nós nos apegarmos à sua forma como o que irá 
trazer o ineditismo ao dispositivo, poderemos ser tragados pelo engodo de transformá-lo em um grupo de estudos com poucos integrantes; ou em uma unidade (composta por alguns) que estudam e entendem da mesma maneira o objeto da pesquisa. Não parece ser essa a proposta de Lacan.

\section{Tempo}

Ainda sobre os efeitos de grupo e unidade, outra particularidade do cartel é que ele teria a duração de, em média, dois anos de trabalho e, depois disso, aquela configuração de cartel teria fim. Assim, ao término desse período, os cartelizantes estariam, novamente, como elos soltos, e novas combinações podem ser feitas.

Mais uma vez, o cuidado com a "garantia" se faz necessário quando falamos no tempo de um cartel. Estamos acostumados a pensar no tempo como naquilo que nos permite o acúmulo de conhecimento e, então, a ideia de que, quando percorremos um período de tempo, teremos, ao fim, conquistado algo novo. A lógica do desenvolvimento humano (escolar, orgânico, fases da vida etc.) está pautada por essa ideia.

Mas, e no cartel? Podemos dizer que houve cartel quando cumpre o tempo de dois anos de funcionamento? Se nos agarrarmos ao tempo como àquilo que diz do ineditismo do dispositivo, poderemos cair no engodo de que esse período de estudos faria com que terminássemos mais psicanalistas do que quando entramos. É possível fazer muitos cartéis e em nenhum deles o sujeito se implicar com o processo de formação como agente. Também não parece ser essa a proposta de Lacan.

\section{Espaço}

A dissolução de um cartel atesta um fracasso? Não é raro associar a interrupção do trabalho e a dissolução do cartel a algo que fracassou, principalmente quando temos no pensamento que o que caracteriza um cartel - como forma e tempo diria tudo sobre ele.

Quando os tomamos como ideais a serem seguidos, há um risco de normatizar um dispositivo que nasceu para fazer resistência à normatividade e à burocratização da psicanálise. Seria possível reconhecer, então, a dissolução como um corte? Este provoca uma descontinuidade capaz de promover a suspensão daquilo que antes se tinha como certo e, em certa medida, inquestionável. Se é o corte que possibilita a irrupção do novo, por que não?

Há apenas uma maneira de reconhecer se algo tem o valor de corte: seus efeitos. Nesse sentido, serão os efeitos da dissolução que dirão o que ela produziu em cada cartelizante; talvez em tempos e de formas diferentes.

Se "incluir a singularidade do cartelizante" é respeitar o “(...) tempo que lhe foi necessário para que ele mesmo a compreendesse, já que essa situação não é outra senão sua própria hipótese (...)" (Lacan, 1945/1998, p. 206), penso que - assim como em uma análise - seria diante dos efeitos que saberíamos que algo aconteceu. 
Efeitos de transmissão, efeitos de produção, efeitos de uma nova posição (nesse caso, diante da própria Escola); ou seja, efeitos de causa.

Para concluir, o que pude recolher até o momento é que, apesar de serem necessárias, as condições para que o cartel aconteça não garantem que encontraremos determinado caminho ou determinada produção; elas possibilitam a suspensão necessária para que algo possa acontecer de inédito. Essa, sim, parece ser a proposta de Lacan ao criar esse dispositivo.

Dito isso, lanço uma nova questão, que é produzida a partir da escrita deste texto: se, no horizonte do cartel, encontramos seu fim, haveria algum cartel que não se dissolve?

“(...) basta que um vá embora para que todos fiquem livres”, diz Lacan (1980/2003, p. 319) quando decide dissolver sua própria Escola. Sim, ele dissolve sua Escola! Dissolver não seria, então, a maior subversão desse dispositivo?

\section{Referências bibliográficas}

Azevedo, A. M. A. (2008). Formação psicanalítica: algumas reflexões sobre a análise didática. Jornal de Psicanálise, São Paulo, 41(74), 179-186.

Lacan, J. (1945/1998). O tempo lógico e a asserção da certeza antecipada. In J.

Lacan. Escritos (Vera Ribeiro, Trad.) (pp. 197-213). Rio de Janeiro: Jorge Zahar. Lacan, J. (1964/2003). Ato de fundação. In J. Lacan. Outros escritos (Vera Ribeiro, Trad.) (pp. 235-247). Rio de Janeiro: Jorge Zahar.

Lacan, J. (1980/2003). Carta de dissolução. In J. Lacan. Outros escritos (Vera Ribeiro, Trad.) (p. 319-320). Rio de Janeiro: Jorge Zahar.

Recebido: 18/04/2018

Aprovado: 19/06/2018 